\title{
CLOSTRIDIUM WELCHII SEPTICAEMIA COMPLICATING PARTIAL GASTRECTOMY
}

\author{
By M. Levene, M.R.C.S.(Eng.), L.R.C.P.(Lond.), D.PATH. \\ Assistant Pathologist, Christie Hospital and Holt Radium Institute, Withington, Manchester
}

Death from Clostridium welchii infection is usually the result of toxaemia. Invasion of the blood stream is uncommon in man, except in cases of induced abortion or as a preagonal bacteraemia. The purpose of this paper is to report a case of fatal infection by this organism after partial gastrectomy.

\section{Case Report}

J.W., aged 38 , a male office worker, was admitted on November 28, 1954, with a 16-year history of indigestion. A diagnosis of chronic duodenal ulcer with gross pyloric obstruction was confirmed radiologically. On January 6, 1955, partial gastrectomy was performed. There was a grossly scarred ulcer in the first part of the duodenum, causing marked stenosis; considerable induration of the adjacent area of the pancreas existed and mobilization of the ulcer was not attempted. The pyloric antrum was transected about $\mathrm{I}$ in. proximal to the pylorus. Approximately two-thirds of the stomach was removed and an antecolic anastomosis performed.

The Ryle's tube was removed after the second day and the patient was taking $3 \mathrm{oz}$. water every hour. Four days after operation he began vomiting during the night and the pulse rate rose to 104, the temperature remaining at $98^{\circ} \mathrm{F}$. He was given 3 oz. milk and water every hour. By January I I the temperature had risen to $100^{\circ}$, and the pulse rate was 120 . The abdomen was grossly distended, the patient being cyanosed and restless. A diagnosis of acute pancreatitis was considered and a serum amylase estimation was 240 Somogyi units (normal 70 to I 50 units). Laparotomy was performed, but no leakage or evidence of infection was found, and the wound was closed. The next day his condition had deteriorated and he died.

Necropsy was carried out 27 hours after death, the body having been removed to the refrigerated mortuary after four hours. The body was that of a well-built male. There was a recent upper midline abdominal incision closed by separate sutures and clips, with a tube emerging from the upper end. The neck was red and swollen and crepitated.

The upper respiratory tract was very red; there was pus in the epiglottis. The lungs were very oedematous, the right weighing $850 \mathrm{~g}$. and the left $590 \mathrm{~g}$. The lower lobes were congested with blood and there were large scattered petechial haemorrhages over the pleural surfaces. Haemorrhages were also present along the posterior atrioventricular groove of the heart.

The peritoneal cavity contained a moderate amount of yellow fluid and fibrinous exudate. The wound surfaces did not show any obvious gas gangrene. The oesophagus was congested and the stomach was full of a rather purulent fluid. The sites of anastomosis were intact. There were two oval ulcers about $\mathbf{I ~} \mathrm{cm}$. in diameter in the duodenal stump. It was difficult to determine whether there had been any leakage at this point. All the intestines were dilated. There was no blood or evidence of ulceration in the bowel.

The liver was a pale terra-cotta colour with a fibrinous exudate over the diaphragmatic surface. There were numerous honeycombed gas bubbles present, especially involving the left lobe. The gall bladder and ducts appeared normal and the pancreas showed some fat necrosis. The spleen (200 g.) was slightly enlarged, but was not ' septic' in appearance. Both kidneys (weighing $310 \mathrm{~g}$. together) were swollen, but the architecture was distinct. The suprarenals were normal, as were all other organs.

\section{Bacteriology}

Swabs were taken from the right lung, the heart blood and the larynx. All cultures yielded a growth of $\mathrm{Cl}$. Welchii. A haemolytic streptococcus, Group B, was also obtained from the larynx. The Cl. Welchii was of Group A, and produced $\alpha$ toxin showing haemolytic and lecithinase activity. Large amounts of viscous material were produced by the capsule.

\section{Histological Examination}

The larynx showed severe haemorrhagic con- 
gestion with mild submucosal inflammatory infiltration. The lungs showed severe haemorrhagic congestion and oedema, with subpleural haemorrhage. There were two chronic duodenal ulcers with no evidence of malignancy. There was gaseous destruction of the parenchyma of the liver and mild biliary tract inflammation. There was an acute perihepatitis. There was abscess formation in the spleen. The kidneys showed generalized toxic change. Gram-stained sections revealed the presence of gram-positive bacilli in the small vessels and the splenic abscesses. Fat embolism was not demonstrated in the lungs.

\section{Discussion}

It is considered unlikely that infection arose from some source outside the body for three reasons. The wound did not show any signs of gas gangrene. Cultures next day from the operating theatre and the routine weekly bacteriological check-up were satisfactory. No similar postoperative infection has been reported here over the past few years.

A septicaemia was not suspected and $\mathrm{Cl}$. Welchii was not isolated from the living patient. The diagnosis rests on the results of bacteriological and histological examination of post-mortem material. Caution, as Learmonth has stated, must then be taken when assigning aetiological significance to such findings. Multiplication of intestinal bacilli in the blood stream after death often produces gas in the parenchymatous organs. Clinically, there had been sudden collapse of the patient after four days. The necropsy findings of the case presented were those of severe shock. The presence of epicardial and pulmonary haemorrhages strongly suggested an overwhelming sudden invasion of the blood stream before death. Cruikshank and Davidson (1944) reported five cases of pulmonary haemorrhage, apparently resulting from an agonal bacteraemia by anaerobic intestinal organisms of the $\mathrm{Cl}$. Welchii type. None of these cases showed epicardial haemorrhage. The primary lesion in each case was in the digestive tract. They were unable to reproduce experimentally such pulmonary haemorrhages as a post-mortem phenomenon.

Cl. Welchii is a normal inhabitant of the human intestine, being constantly present in small numbers. The acidity of the healthy stomach, duodenum and jejunum is sufficiently great to kill most organisms, apart from $M$. tuberculosis and $E$. histolytica. The organism has been found in increased numbers in the intestinal tract in certain pathological states and its role discussed in a recent leading article of the Lancet (February 9, 1955). Type A has been suggested as a causal factor in the production of mild forms of food poisoning and various intestinal disorders, including the diarrhoea after gastrectomy (Howie et al., 1953). Type F has been implicated in the condition of 'enteritis necroticans' described by Zeissler and Rassfeld-Sternberg (1949). Type D has now also been demonstrated in cases of colitis (Kohn and Warrack, 1955) and a case of acute obstruction of the small intestine (Gleeson-White and Bullen, 1955). The presence of $\mathrm{Cl}$. Welchi alone is apparently not enough to produce intestinal disturbance. The main problem to be answered, assuming the organism is already present in the body, is what alters a pre-existing state of affairs and renders the body liable to attack.

Barber and Franklin (1946) isolated monilia albicans, non-haemolytic streptococci and coliform bacilli from the stomachs of patients with a normal or high gastric acidity, but did not find $\mathrm{Cl}$. Welchii. Somervell (1948) contrasted this with the frequent finding of $\mathrm{Cl}$. Welchii in his patients in India. Seley and Colp (194I) investigated the bacteriology of peptic ulcers and gastric malignancies after sub-total gastrectomy and isolated intestinal micro-organisms from them. In order of frequency, the organisms were $S$. viridans, haemolytic and faecal streptococci, $B$. coli and $B$. Welchii. Unexpectedly they found $B$. Welchii in seven cases and to their knowledge this fact had not been previously recorded. Everyone of these seven cases either developed a serious complication of died. They concluded that the finding of $B$ : Welchii was of real clinical and prognostic significance.

In 1924 Learmonth reported a case of metastatic gas gangrene in a 35-year-old male who presented with perforation of a chronic gastric ulcer. Three days after operation the patient became gravely ill and his pulse rate rose to $120 . C l$. Welchii was isolated from a purple crepitant swelling of the right arm. The author was convinced that the infection had originated in the alimentary tract, although the actual portal of entry into the blood stream was obscure. He suggested that possibly the organism had been present in the stomach at operation or that some minute part of the bowel may have been damaged. Ghormley (1935) reported a series of 33 cases of gas gangrene, six of which followed operations upon the gastrointestinal tract. One case of pneumonia where Cl. Welchii was recovered from the sputum was also described. In $1952 \mathrm{~A}$. E. O’Donnell reported a case of primary clostridial pneumonia after partial gastrectomy for duodenal ulceration with pyloric stenosis. He suggested that the infection had arisen from the nose. One ventures to suggest that this interpretation of the origin of the infection was erroneous. Evidence thus exists suggesting that injury to the gastro-intestinal tract may allow 
entry of gas-forming organisms into the blood stream.

A striking feature is the unusualness of such a complication in an operation which is performed successfully daily with an immediate fatility rate of less than 4 per cent. (Aird, I949). Blood stream invasion depends on the anatomy and functional activity of the tissues first invaded and upon the virulence of the invading micro-organism. Some factors which might help explain the development of this overwhelming infection are the sudden removal of a hyperchlorhydric state, the presence in the abdomen of devitalized tissues, and the effect of intestinal stasis. Experimental evidence in dogs also suggests that deficiency of vitamins B and $\mathrm{C}$, and particularly states of under-nourishment, rendered them more susceptible to $\mathrm{Cl}$. Welchii infection (Rose, Rose and Kolmer, 1936). Caseinogen in milk may further reduce the $p \mathrm{H}$ of gastric juice (Freezer, 1928). Roberts (1938) suggested that the entero-toxaemia of lambs might be due to dilution of gastric contents with casein. $\mathrm{He}$ demonstrated that large amounts of $\mathrm{Cl}$. Welchii Type $\mathrm{D}$ culture given by mouth were readily killed by lambs' gastric juice. If casein was given with the organisms, these were protected in some way and the disease state was produced. It is possible that all these factors played some part.

\section{Conclusion}

It is suggested that infection of the blood stream by $\mathrm{Cl}$. Welchii is a real though rare danger in gastric surgery. It should be borne in mind when a patient suddenly collapses in a state of shock with a rise in pulse rate. Blood cultures, administration of antibiotics and anti-gas gangrene serum may be necessary. Gram-stained sections of necropsy tissue may help explain some cases of an early death after gastrectomy.

\section{Acknowledgments}

I am indebted to Mr. A. Nicholson for permission to publish, to Drs. D. G. Evans and Perkins, of the Manchester University Department of Bacteriology, for their assistance in the bacteriological typing and to Dr. Stent and her technical staff for their help.

\section{BIBLIOGRAPHY}

AIRD, I. (1949), 'A Companion in Surgical Studies,' Edinburgh, p. 549.

BARBER, M., and FRANKLIN, R. H. (1946), Brit. med. f., i, 951 . CRUIKSHANK, A. M., and DAVIDSON, J. I. (1944), $\mathcal{f}$. Path. Bact., 56, 37.

FREEZER, C. R. E., GIBSON, C. S., and MATHEWS, E. (1928), Guy's Hosp. Rep., 78, 191.

GHORMLEY, R. K. (1935), f. Bone ft. Surg., 27, 907.

GLEESON-WHITE, M. H., and BULLEN, J. J. (1955), Lancet, i, 384 .

HOWIE, J. W., DUNCAN, I. B. R., and MACKIE, L. M. (1953) Ibid., ii, ror 8.

KOHN, J., and WARRACK, G. H. (1955), Ibid., i, 385.

Leading Article (1955), Ibid., i, 390.

LEARMONTH, J. R. (1924), Ibid., ii, 648.

O'DONNELL, A. E. (r952), Ibid., ii, 367.

ROBERTS, R. S. (1938), Vet. Rec., 50, 591.

ROSE, S. B., ROSE, W. B., and KOLMER, J. A. (1936), $\mathcal{F}$. infect Dis., 59, 50.

SELEY, G. P., and COLP, R. (1941), Surgery, 10, 369.

SOMERVELL, T. M. (1948), 'Surgery of the Stomach and Duodenum,' Arnold, London, p. 138.

WILLIAMS, B. W. (I927), Lancet, i, 907.

ZEISSLER, J., and RASSFELD-STERNBERG, L. (1949), Brit. med. $\mathcal{F} ., 1,267$.

\section{RUTHIN CASTLE, NORTH WALES}

A Clinic for the diagnosis and treatment of Internal Diseases (except Mental or Infectious Diseases). The Clinic is provided with a staff of doctors, technicians and nurses.

The surroundings are beautiful. The climate is mild. There is central heating throughout. The annual rainfall is 30.5 inches, that is less than the average for England.

The Fees are inclusive and vary according to the room occupied.

For particulars apply to THE SECRETARY, Ruthin Castle, North Wales. 